\title{
Discutindo as Histórias em Quadrinhos enquanto recurso didático em Ciências
}

\section{Discussing the Workshops with Comics as a teaching resource in Science}

\author{
${ }^{1}$ Elienae Genésia Corrêa Pereira elien2@ig.com.br \\ ${ }^{2}$ Helena Amaral da Fontoura
}

\section{RESUMO}

Ainda hoje observamos atividades de ensino pautadas no paradigma positivista. Todavia, estudos evocam reflexões sobre a necessidade de uma postura pedagógica que desenvolva a criatividade e a expressividade do aluno, propiciando a construção do saber de forma descontraída e prazerosa. Neste sentido, este artigo, parte de uma tese de doutoramento, aborda o potencial educativo da literatura em quadrinhos ao analisar e discutir aspectos positivos da inserção de Oficinas de Histórias em Quadrinhos (OHQ) como recurso didático no ensino de Ciências. Os resultados indicam que as OHQ constituem-se em um instrumento didático versátil, abrangente e dinâmico, que favorece a criatividade dos alunos e o desenvolvimento de um processo cognitivo questionador, crítico e contextualizado, dentro do contexto interdisciplinar.

Palavras-chave: Literatura em quadrinhos, recurso pedagógico, ensino de ciências, sequência didática.

\section{ABSTRACT}

Even today we see teaching activities based on the positivist paradigm. However, studies show reflections on the need for a pedagogical approach that develops creativity and expressivity of the student and that provides the construction of knowledge in a relaxed and enjoyable way. In this regard, this article, part of a doctoral thesis, emphasizes the educational potential of using comic literature and analyses and discusses the positives inserting of Workshops with Comics (WSC) as a teaching resource in science teaching. The results show that the WSC constitute into a versatile, comprehensive and dynamic teaching tool, favouring the creativity and the development of a questioning, critical and contextualized cognitive process, within the interdisciplinary context.

Keywords: Comic literature, pedagogical practice, science teaching, didactic sequence.

1 Docente - Secretaria Municipal de Educação / Doutoranda - Instituto Oswaldo Cruz.

2 Docente - Faculdade de Formação de professores/Universidade Estadual do Rio de Janeiro e Programa de Pós-Graduação em Ensino em Biociências e Saúde/Instituto Oswaldo Cruz. 


\section{INTRODUÇÃO}

Vivemos em uma época muito peculiar em que o avanço da tecnologia aliado a uma cultura calcada na economia de mercado, bem como o desejo de concentração de poder por parte de pequenos grupos leva a adoção de políticas que dificultem a ascensão sociocultural e econômica de boa parte da população. Este panorama social tem refletido na educação, nas políticas adotadas para o ensino formal, na pouca valorização do educador enquanto profissional, na constante falta de recursos para o ensino.

Tudo isto vem favorecendo a permanência do paradigma positivista como base do mecanismo de ensino-aprendizagem em nossas escolas, apesar dos tantos estudos e discursos contemporâneos que evocam a necessidade de um ensino contextualizado, questionador, dinâmico, que tenha significado e voltado para o aluno como ser social e crítico, que se deseja participante na sociedade (FREIRE, 1997; 2001; FREINET, 1966; 1974; MOREIRA, 1999; 2011; VYGOTSKY, 1988; 1991).

Caruso e Silveira (2009) ressaltam que o ambiente escolar normalmente não é entendido como um espaço de diálogo, que estimule o debate de ideias e propostas, mas como um ambiente de grande potencial castrador, onde para o educando a dúvida é vergonhosa, o professor é o detentor do conhecimento (dono da verdade) e o aluno aquele que ignora, que desconhece totalmente.

Promover situações que despertem o interesse dos alunos (e sua criatividade) é um importante papel da escola, levando os alunos a descobrir (e a querer descobrir) o novo (PEREIRA; FONTOURA, no prelo b). Outro aspecto a ser salientado é a necessidade de superação da fragmentação do saber através de uma postura interdisciplinar, conforme preconizado pelos Parâmetros Curriculares Nacionais (1997). Entretanto, temos notado que a inserção de práticas educativas mais interativas e lúdicas, que extrapolem a sala de aula não é comum à prática docente. Como adverte Freinet (1966), a função educativa não está limitada aos muros da escola, pois “a criança tem necessidade de agir, criar e trabalhar, isto é, empregar a sua atividade numa tarefa individual ou socialmente útil” (Ibid, 1974, p. 49), durante as quais os saberes oriundos do cotidiano dos alunos devem ser respeitados.

Considerando a reflexão de Paulo Freire (1997) de que o ato de ensinar não é meramente transmitir conhecimento, mas gerar possibilidades para sua produção ou sua construção pelos próprios educandos, acreditamos ser imprescindível à realização de práticas pedagógicas que propiciem a internalização de construtos socioculturais em uma perspectiva crítica, inseridas em um contexto de interatividade, reconhecimento e respeito ao outro e de cooperação, sabendo que a escola precisa ir além da simples memorização de conteúdos. Perante esta perspectiva, Fanaro e colaboradores (2005) alertam que pesquisas na área de ensino de Ciências indicam novas orientações que destacam a análise das dimensões discursivas e imagéticas no processo ensino-aprendizagem em situações do cotidiano escolar e a importância da linguagem como elemento crucial para a aquisição e expressão do conhecimento científico. Em consonância, Carvalho e Barbeiro (2013) comentam que a escrita, enquanto instrumento de aprendizagem, tem sido tratada com mais atenção em vários contextos e situações, citando o movimento Writing Across the Curriculum (WAC), desenvolvido nos Estados Unidos a partir da década de 1970, que entende a escrita tanto como meio de comunicação quanto de aprendizagem em um contexto inter e transdisciplinar, independente do nível de ensino; e movimento Science Writing Heuristic, que tem tido destaque no que concerne a investigação em ensino de Ciências sobre as potencialidades pedagógicas que decorrem do uso da escrita nos processos de aquisição, elaboração e comunicação do conhecimento científico.

Com efeito, Fontoura e colaboradores (2011) advertem que a instituição escola tem a responsabilidade de contextualizar e significar a compreensão e participação de seus discentes no mundo, onde o conhecimento que nela é construído está relacionado às diversas leituras de mundo e aos diversos saberes científicos e empíricos, o que torna a interdisciplinaridade fundamental - segundo a concepção de Fazenda (2002) e Augusto e Caldeira (2007), que a caracterizam como uma relação de reciprocidade, possibilitando o diálogo entre os atores atuantes no processo pedagógico, na qual a colaboração entre as disciplinas conduz a uma interação das partes em um todo. 
Desde a década de 1960, as Histórias em Quadrinhos (HQs) têm se propagado no âmbito do ensino formal, a princípio sendo utilizadas em aulas de Língua Estrangeira e Língua Portuguesa e, posteriormente, em outras áreas, ganhando destaque como ferramenta pedagógica ao tratar de diversos assuntos como Matemática, Comunicação e Expressão, Ciências Físicas e Biológicas, História, Moral e Civismo, Religião, como nos aponta Silva (1985). Entretanto, até o início da década de 1990, antes da implantação dos Parâmetros Curriculares Nacionais (PCN), elas não eram bem aceitas pela comunidade escolar, sendo, recentemente, incluídas como gênero de leitura necessário à educação, com o apoio do Programa Nacional Bibliotecas na Escola (SILVA, 2011). Todavia, para Cirne (2000), mesmo hoje - início do século XXI - ainda é inegável a existência de preconceito artístico e cultural contra as HQs.

Os quadrinhos são amplamente difundidos em jornais e revistas, tornando-se um expressivo meio de comunicação de massa tendo sua linguagem e personagens sido incorporados em outros veículos artísticos de comunicação, como o cinema e a televisão. Suas imagens, falam por si, donde encontramos inúmeras HQs que permitem sua interpretação mesmo por aqueles que ainda não aprenderam a ler, a exemplo de crianças da Educação Infantil, além do fato de as imagens fornecerem significado a linguagem escrita.

Segundo Linsingen (2007), a literatura em quadrinhos se constitui em uma forma de arte sequencial que informa e educa, sendo estruturada pela imagem e pela escrita e configurando-se como uma forma de comunicação instantânea e intencional. Ao mesmo tempo, possuem uma linguagem verbal e não verbal objetiva e popular vinculada ao cotidiano, onde a ação está presente, perpassando a ideia de movimento, de 'língua falada' e onde se nota vários fatos/acontecimentos ao mesmo tempo, de maneira simples e divertida. De acordo com Vygotsky (1991), fala e escrita estão intimamente relacionadas, pois são recursos de comunicação com o outro, onde a primeira normalmente é uma forma mais elaborada de linguagem, que exige certo rigor em sua estruturação, enquanto a fala (expressão oral), por estar combinada a suportes de expressão corporal e situacionais, é mais livre.

Neste sentido, ao unirem códigos verbais e não verbais, utilizando a língua falada para a elaboração de seus textos, representando a oralidade, as HQs são mais bem compreendidas pelos alunos da Educação Básica (PEREIRA; SANTOS, 2013). Consoante a este pensamento, Moya (1977) afirma que as crianças apresentam dificuldades em compreender a literatura feita para elas, pois não estão familiarizadas com sua estrutura, seu vocabulário e seu sistema de imagens e ideias, o que não ocorre com as HQs que combinam a imagem com o texto escrito articulando temas do cotidiano. Os quadrinhos configuram-se em uma literatura que reflete as ideias da sociedade da época, sem mencionar que suas mensagens possuem diversas intenções como informar, seduzir, divertir, convencer, entre outras (CIRNE, 2000).

No contexto do ensino de Ciências, Pizarro (2009) mostra que a literatura da área já evidencia a relevância do uso de HQs enquanto instrumento pedagógico, havendo publicações, nacionais e internacionais, descrevendo e discutindo diferentes experiências realizadas com este recurso.

Com este entendimento, e reconhecendo a relevância deste tema perante a literatura, este artigo se propõe a analisar e discutir a utilização de Oficinas de Histórias em Quadrinhos (OHQ), na concepção de sequências didáticas, como instrumento pedagógico para aulas de Ciências, contribuindo, desta forma, para o aumento do conhecimento sobre essa ferramenta e suas contribuições para o campo educacional.

\section{CAMINHO METODOLÓGICO}

Este trabalho, parte da discussão teórica de um estudo mais amplo de doutoramento sobre a ampliação da ação docente, consiste em uma pesquisa bibliográfica exploratória apoiada na contextualização e discussão com autores da área dos resultados e conclusões de 20 estudos voltados para o uso de HQs enquanto ferramenta didática. Oito deles abordam o seu uso enquanto proposta textual, aproveitando HQs comerciais ou produzidas especificamente para determinado tema (BAHLS; REZENDE, 2011; CARVALHO; OLIVEIRA, 2004; MEHES; 
MAISTRO, 2012; PALHARES, 2008; PIZARRO, 2009; SANTOS; PEREIRA, 2013a; TESTONI, 2004; VARGAS; MAGALHÃES, 2011) e os outros doze abordam a criação de historinhas, durante OHQ, pelos sujeitos de pesquisa - docentes de Língua Portuguesa (BOFF, 2000), alunos do $4^{\circ}, 6^{\circ}, 8^{\circ}$ e $9^{\circ}$ anos do Ensino Fundamental, com idades entre 9-15 anos (PEREIRA, 2008; PEREIRA; FONTOURA, no prelo a; PEREIRA; SANTOS, 2009; SANTOS; PEREIRA, 2009; 2011; 2013b; PIZARRO, 2009; TESTONI, 2004), alunos do Ensino Médio (CARUSO; SILVEIRA, 2009) e alunos de licenciatura em Química (PEREIRA; SANTOS, 2013a; 2013b).

É importante explicarmos que o foco principal desse trabalho foi a análise dos estudos sobre a utilização de OHQ no cenário do ensino-formal como recurso pedagógico em um contexto de ensino de Ciências, principalmente aqueles realizados pelas autoras. Cabe também explanar que, em todas as pesquisas com OHQ realizadas pelas autoras, foi utilizada a mesma metodologia, onde os participantes criaram HQs mediante um tema de ciências proposto seguindo a uma sequência didática com três etapas: um primeiro momento para a familiarização com o gênero literário dos quadrinhos com a utilização de tirinhas e fragmentos de HQs comerciais; um segundo momento visando a desmistificação do ato de desenhar através de uma dinâmica para a produção de desenhos, como por exemplo, expressões faciais e vários tipos de árvores; e um terceiro momento que consistiu na produção efetiva da HQs. Ao longo de todas as etapas das OHQ propostas pelas autoras, os sujeitos participaram de vários momentos de interação e discussão em grupos, visando favorecer a troca de conhecimentos e a (re)construção do saber em uma concepção interdisciplinar. A metodologia dessas OHQ está explicitada mais detalhadamente nos estudos Pereira (2008) e Santos e Pereira (2011).

\section{RESULTADOS}

\section{1 HQs: Fator enriquecedor do ato de ler, interpretar e contextualizar.}

Há algum tempo tem sido discutido o desinteresse das crianças, adolescentes e jovens pela leitura, tanto no âmbito escolar quanto no meio acadêmico, o que, segundo Santos (2003), é uma questão desencadeada por diversos fatores de ordem socioeconômica e política (situação das escolas, falta de incentivo à leitura, falta de bibliotecas), e não apenas em função da popularização da televisão, do videogame e da Internet.

Lembramos que, para que se desenvolva o hábito de ler, é necessário que se tenha prazer, que exista o sentimento de 'necessidade' de saber/conhecer/descobrir, pois somos seres sociais. Quando este hábito realmente existe, a leitura também se torna uma ação divertida, cheia de emoções. Assim, cabe aos educadores a tarefa de estimular seus alunos e propiciar condições favoráveis para o desenvolvimento deste hábito.

A literatura tem feito referências ao preconceito existente da inserção de estratégias didáticas que envolvam HQs no ensino formal. O que averiguamos, todavia, em pesquisas abordando este recurso (a exemplo de BAHLS; REZENDE, 2011; BOFF, 2007; CARUSO; SILVEIRA, 2009; KAMEL, 2006; MACHADO, 2009; PALHARES, 2008; PEREIRA, 2008; PEREIRA; FONTOURA, no prelo a; PEREIRA; SANTOS, 2013a; 2013b; PIZARRO, 2009; SANTOS, 2008; TESTONI, 2004; VARGAS; MAGALHÃES, 2011), desenvolvidas com crianças, adolescentes e jovens, foi a ausência de qualquer demonstração de preconceito pelos sujeitos no que se refere à sua linguagem, aceitação ou legitimidade cultural.

Analisando as pesquisas que integram esta investigação, verificamos que em todos os grupos estudados os participantes conheciam a linguagem usada nas HQs, estando familiarizados com sua estrutura. Em sua maioria, os sujeitos demonstraram apreciar este tipo de literatura por proporcionar uma leitura fácil, rápida e divertida. Vale frisar que as HQs têm um apelo visual forte e seu timing está compatível com o timing da visão fragmentada dos videoclips, permitindo uma leitura dinâmica da mensagem transmitida, sendo um recurso didático estimulante (CARUSO; SILVEIRA, 2009). 
Para Santos (2003), a criança que não lê HQs não terá disposição para ler outros textos literários (sejam informativos, didáticos ou de entretenimento). Concordamos com o autor quanto à validade da utilização das HQs na iniciação e consolidação do hábito de ler nos jovens. Não obstante, observa-se que os docentes vêm utilizando cada vez mais a literatura em quadrinhos, principalmente aproveitando tirinhas já existentes (comerciais) como textos para motivação e contextualização de temas relacionados às suas aulas (SILVA, 2011). Neste sentido, nas pesquisas que realizamos em escolas da Educação Básica pudemos constatar esta prática basicamente na área de Língua Portuguesa e, de forma menos expressiva, na área de Língua Estrangeira, utilizando-se de tirinhas propostas nos livros e/ou apostilas e retiradas de jornais e revistas e, em poucos casos, usando histórias de revistas em quadrinhos (SANTOS; PEREIRA, 2011).

Tanto em nossos estudos quanto nos de outros autores, nas disciplinas de Ciências e de História as HQs surgiam timidamente e apenas em forma de tirinhas e/ou charges em algumas apostilas e em livros didáticos. Em todos os casos as HQs foram usadas essencialmente como substitutas de textos interpretativos, introdutórios ou de fixação e como ferramenta para ilustrar ou exemplificar um evento ou uma situação. Outro aspecto observado nos trabalhos analisados foi o uso de HQs como base para discussões/debates. É relativamente comum no ensino formal, principalmente em disciplinas da área de humanas e de comunicação, o trabalho com textos extraídos de jornais, revistas e/ou adaptados para tal pelo professor ou pelo livro didático e, em menor escala, os quadrinhos.

Nossa proposta, até este momento, foi avaliar as pesquisas sobre atividades que envolveram a leitura de HQs como ferramenta introdutória para a apresentação de um tema específico, configurando-se como o ponto de partida das discussões iniciais do mesmo durante estudos com alunos Ensino Fundamental e Médio (MEHES; MAISTRO, 2012; PEREIRA, 2008; PIZARRO; LOPES JR, 2009) e com licenciandos em Química (PEREIRA; SANTOS, 2013a; 2013b; SANTOS; PEREIRA, 2013a). Nesses estudos, as HQs se mostraram instigantes, provocativas e capazes de levar para a sala de aula o cotidiano, a realidade vivenciada, mesmo em se tratando de um saber científico, indicando sua relevância no desenvolvimento da aprendizagem nos alunos. Frente a esta observação, Silva e colaboradores (2011) comentam que por serem objetivas e divertidas e estarem muito próximas da realidade das pessoas, as HQs se identificam melhor com o leitor.

No estudo com os licenciandos (PEREIRA; SANTOS, 2013a; 2013b; SANTOS; PEREIRA, 2013a) também foi constatado que os participantes somente vislumbraram as HQs como uma estratégia pedagógica no ensino de Ciências após terem vivenciado a atividade com as tirinhas, colocando que as mesmas incentivariam os alunos à leitura. Este resultado condiz com a afimação de Moreira (1999) de que a diversidade dos materiais instrucionais em substituição ao livro didático é legítima e necessária no decorrer das aulas e corroboram com os PCN (1997) que enfatiza a associação de textos a imagens como um fator que auxilia os discentes no desenvolvimento da leitura.

Vale ressaltar que na sociedade em que vivemos, sujeita a constantes e rápidas mudanças e onde emergem novas informações (conhecimentos) a todo instante, é inevitável que as pessoas saibam pensar contextualizada e criticamente, discernindo e delineando o caminho que querem seguir. $\mathrm{O}$ ato de ler e interpretar um texto, principalmente aqueles que remetem às vivências do leitor, pode favorecer o seu 'aprender a pensar'.

\section{2 HQs: processo de construção em Ciências através de oficinas de criação.}

As HQs têm adentrado a sala de aula como um instrumento literário para trabalhar-se o processo de interpretação de textos (incentivando a leitura através de quadrinhos 'comerciais'), a quadrinização de textos em livros didáticos, adaptação de obras literárias, retratação de acontecimentos históricos ou como precursoras de debates em aula (SANTOS, 2003; SANTOS, 2007; SANTOS; VERGUEIRO, 2012). No entanto, Caruso e Silveira (2009) alertam que educadores de diversas áreas vêm aproveitando cada vez mais os quadrinhos, (re) inventando o seu uso enquanto proposta pedagógica. Os autores propõem e discutem a criação de HQs por 'alunos artistas', inseridos em um projeto de educação não formal (Oficina de Educação Através de Histórias em Quadrinhos e Tirinhas - Eduhq) visando à divulgação científica. 
Pizzarro e Lopes Jr. (2009), em um trabalho em que alunos do $4^{\circ}$ ano do Ensino Fundamental produzem HQs e depois as discutem com os colegas, constata a ocorrência de um processo mais dinâmico e interativo de aprendizagem, além de um forte interesse por parte das crianças, fato também observado em nossos trabalhos com discentes do $6^{\circ}$ ao $9^{\circ}$ ano do Ensino Fundamental, com uma maior faixa etária. Neste sentido, Moreira (1999) afirma que aprender é modificar, descobrir, inventar, é agir sobre o conhecimento, cabe, então, ao educador propiciar situações diversas para que o educando construa seu sistema de significação.

Nos momentos iniciais das oficinas, foi evidenciado que todos os grupos estudados mostraram-se curiosos quanto à atividade em si e aos seus objetivos, mesmo o grupo de licenciandos formado por jovens e adultos, em função da novidade de comporem uma HQ. Entretanto, os sujeitos, principalmente no grupo de adultos, a princípio apresentaram-se um pouco relutantes quanto o 'ter que desenhar' as HQs. A preocupação básica era relativa às suas habilidades em 'desenhar perfeitamente’ as ilustrações, o que lhes foi esclarecido não ser necessário, pois o que importava era que exprimissem suas ideias e percepções. Concordamos com Boff (2000) quando diz que, durante o processo de criação do aluno, o professor deve incentivá-lo ao exercício de sua capacidade de expressão, não importando a obra final.

Durante as discussões realizadas nos pequenos grupos (ou duplas) ao longo da construção das historinhas, os estudos indicaram um mecanismo de mútua colaboração, em um exercício de reflexão e argumentação, sobretudo em relação ao que seria dito (informações e conteúdos a serem usados) e em aspectos ortográficos e gramaticais. Este quadro configura-se como um fator preponderante para a ocorrência de uma aprendizagem mais contextualizada, reflexiva e significativa, pois, segundo Vygotsky (1988), não se concebe a aquisição de significados sem que haja interação social; é mediante a interação social que o aluno pode garantir que captou os significados socialmente compartilhados em determinado contexto. Vygotsky (1991) ainda salienta que a fala é um fator importante na organização do pensamento da criança, pois, à medida que ela se expressa oralmente, relatando suas experiências ou inventando uma história, ela elabora e organiza os acontecimentos (estrutura início, meio e fim), percebe e preenche lacunas, estendendo e ampliando seu discurso.

As atividades em grupo oferecem oportunidades pedagógicas diversas. Destacamos aqui o favorecimento de o aluno modificar seu comportamento social (o grupo passa a importar mais do que seu desejo de imposição de sua personalidade), aprendendo a importância de compartilhar e controlar suas emoções, e, então, passa a sentir-se mais capaz e confiante para explorar novos saberes. Berger e Luckmann (1985) apoia esta linha de pensamento ao advertir que para as pessoas tomarem consciência de sua realidade, é indispensável que haja o diálogo com o outro, permitindo sua própria objetivação.

Outro dado interessante a ser apresentado refere-se à comparação que os participantes do Ensino Fundamental fizeram entre as HQs que criaram e os textos que costumam elaborar durante as aulas (redações, respostas discursivas, resumos), colocando que se sentiram mais à vontade, que puderam expressar melhor suas ideias com a ajuda dos desenhos, mesmo quando estas atuariam como instrumento de avaliação por suas professoras de Ciências, além de frisarem que os textos mais tradicionais são 'chatos' e 'complicados de fazer' (PEREIRA, 2008; PEREIRA; FONTOURA, no prelo a; PEREIRA; SANTOS, 2009; SANTOS; PEREIRA, 2009, 2011 e 2013b). Esta percepção também foi evidenciada pelos docentes (tanto de Ciências quanto de Língua Portuguesa) das turmas participantes, que mencionaram ter certa dificuldade em despertar o interesse e o desejo nos alunos de compor uma redação ou escrever um pequeno texto (Ibid).

É oportuno lembrar o pensamento de Abrahão de que texto e ilustração se ajustam na identificação de seus significados e suas relações, testando-se na forçosa integração de matéria e forma, que atende aos princípios atuais da Pedagogia, calcados no caráter sincrético e globalizador do pensamento da criança (apud MOYA, 1977). O pedagogo também discorre sobre o aprendizado indireto, que se dá paralelamente à instrução formal, permitindo a aquisição do conhecimento e a sua (re)construção, decorrente do uso dos quadrinhos. Neste panorama, trazemos uma contribuição de Caruso (2009): 
Os quadrinhos e as tirinhas podem ser importante instrumento capaz de motivar o aluno para a leitura e para os estudos. Eles ensinam o aluno a construir uma narrativa, imaginando e criando o que está subentendido entre um quadrinho e outro na sequencia da história. Contribuem, portanto, para o desenvolvimento da própria linguagem, do poder de síntese, da criatividade e de conceitos importantes. (p. 233).

Reiterarmos, neste momento, que as OHQ propostas proporcionaram espaços para a socialização e discussão das historinhas durante sua composição, visando não apenas facilitar sua construção, mas, principalmente, promover a aprendizagem e até mesmo a consolidação da mesma, visto que as trocas sociais com este propósito são enfatizadas na literatura vigente, como Piaget (1976) e Vygotsky (1988). Estas foram utilizadas com dois objetivos distintos, nos diferentes estudos analisados: enquanto ferramenta para a introdução de um novo assunto ou conteúdo (visando identificar as impressões prévias dos discentes) e enquanto ferramenta de avaliação.

Quanto às possibilidades das $\mathrm{OHQ}$ como proposta metodológica introdutória, constatamos ser bastante diversificada e abrangente, pois permite trabalhar com temas variados, podendo estes ser muito próximos do conteúdo a ser ensinado ou, ao contrário, estar mais relacionado à realidade do aluno. Segundo os dados apresentados nos artigos referentes às $\mathrm{OHQ}$, nas duas formas de abordagem, elas produziram bons resultados no que concerne à identificação das percepções e concepções prévias dos alunos e como motivadoras do interesse destes pela temática trabalhada, facilitando, assim, o processo ensino-aprendizagem. Os docentes frisaram que os alunos tiveram uma participação mais ativa e estavam mais familiarizados com o assunto, levando, inclusive questionamentos e materiais para a aula. Segundo duas professoras entrevistadas:

A turma que fez a OHQ rendeu muito mais na aula, quando fui dar o conteúdo. Eles haviam pesquisado em jornais, revistas e [...] a participação da turma de uma maneira geral foi muito boa.

Docentes de Ciências - Turmas de $9^{\circ}$ Ano (SANTOS; PEREIRA, 2013b)

Em todos os estudos que analisamos, os docentes também destacaram o aprimoramento das discussões e o melhor desenvolvimento das aulas, possibilitando ao aluno expor suas dúvidas e desenvolver sua criatividade, ideia sustentada por Rama e colaboradores (2004) quanto à criação de HQs quando dizem que "atividades como essas também contribuirão para que os estudantes desenvolvam a criatividade, muitas vezes desestimulada no ensino tradicional” (p. 128). Além disto, as turmas que participaram da OHQ usada como recurso de sistematização das concepções prévias e consolidação da aprendizagem obtiveram resultados superiores nas avaliações a que se submeteram posteriormente comparando-as às turmas que não participaram da atividade (PEREIRA; SANTOS, 2009; SANTOS; PEREIRA, 2011 e 2013b). Conforme Linsigen (2007), ao unirmos texto e desenho, tornamos mais claros para a criança conceitos que continuariam abstratos se confinados unicamente à palavra.

Ao analisarmos os estudos onde as OHQ atuaram como instrumento de avaliação, cujo tema central foi proposto pelas pesquisadoras ou pelas professoras das turmas, nos remetemos a Saul (1994) ao afirmar que não só o rendimento cognitivo do aluno, mas inúmeros objetos incidem sobre os processos avaliativos. Nestas pesquisas, observamos que a maioria dos alunos elaborou suas HQs coerentemente, sem fugir da temática proposta, desenvolvendo uma sequência lógica, inserindo termos de cunho científico específicos às temáticas trabalhadas e, em alguns casos, apresentando um sensível aprofundamento no que diz respeito aos conteúdos abordados pelas professoras (PEREIRA; FONTOURA, no prelo a; PEREIRA; SANTOS, 2009; SANTOS; PEREIRA, 2011 e 2013b). As poucas HQs que trataram e/ou inseriram outros tópicos o fizeram correlacionando-os com o tema central. Como a exemplo de historinhas criadas por dois licenciandos, onde ambos ampliaram os conhecimentos discutidos ao longo do curso em um mecanismo de inter-relação entre estes e seus concepções prévias, propiciando a produção de novos saberes (PEREIRA; SANTOS, 2013a).

Nestas pesquisas, os docentes relataram ter ocorrido a consolidação dos conteúdos avaliados através da linguagem própria das HQs - texto e imagem associados, a exemplo do trecho transcrito a seguir: 
[...] é como numa questão discursiva, tipo ‘fale sobre anorexia'. Eles teriam que falar com suas próprias palavras, só que de forma mais formal.

Docente de Ciências - C1-T8 (SANTOS; PEREIRA, 2013b)

Parafraseando Soares e Ribeiro (2001), o processo avaliativo precisa ser contínuo, mapeando e diagnosticando o desenvolvimento da aprendizagem, indicando avanços e questões que precisam ser revistas de modo a possibilitar aos docentes e discentes a superação das dificuldades. Este processo, deve ter uma dimensão não-linear, com várias articulações, tanto com aspectos quantitativos quanto qualitativos, de forma sistemática e integral (FONTOURA et al., 2011).

A partir dos resultados apresentados em todos os trabalhos analisados, verificamos ainda que as OHQ proporcionaram um ambiente favorável ao desenvolvimento da criatividade e à expressão crítica das percepções dos sujeitos de maneira autônoma e vinculada ao seu contexto sociocultural, dentro de uma perspectiva de aprendizagem com significado, distinta de uma mera repetição de informações, de uma assimilação mecânica.

Cabe aqui nos reportarmos a Freire (1997) ao alertar-nos que não há validade no ensino que não gera um aprendizado em que o educando não adquira a capacidade de recriar ou refazer o que lhe foi ensinado. Neste sentido, os estudos indicaram que, durante o processo de elaboração das HQs (permeado de debates entre os grupos), os alunos vivenciaram momentos em que expuseram e discutiram suas percepções, seus conhecimentos e suas emoções a partir de situações concretas, relacionando-as com os conhecimentos adquiridos na escola, tomando decisões e justificando-as no grupo, expressando sua subjetividade.

Em relação à visão dos docentes e futuros docentes (licenciandos) quanto à viabilidade das OHQ funcionarem como uma proposta de avaliação didática, os estudos mostraram uma postura favorável ao seu uso. Em contrapartida, eles apontaram a necessidade de mais tempo para a sua realização, que as OHQ não deveriam avaliar temas/assuntos muito amplos e que os professores teriam que estar cientes de que a avaliação não poderia ser calcada exclusivamente no texto (simplificado e curto), mas também nas imagens e na sequência dada a elas. $\mathrm{O}$ fato das $\mathrm{OHQ}$ não possuírem conotação de uma avaliação formal e de permitir uma maior liberdade de expressão foi outro ponto positivo elucidado pelos docentes (PEREIRA; SANTOS, 2013a; 2013b; SANTOS; PEREIRA, 2011; 2013b).

O que evidencia uma aprendizagem com significado é o fato de o aluno conseguir resolver um problema desconhecido, sendo desta forma imprescindível que situações problematizadoras lhes sejam apresentadas, o que irá permitir a aplicação de seus conhecimentos (preexistentes e novos) e evitar respostas memorizadas (PEREIRA; FONTOURA, no prelo a). Reforçando esta perspectiva, Gomes e colaboradores (2006) enfatizam que para uma prática pedagógica conduzir à autonomia, à ocupação significativa no mundo por parte dos sujeitos e a uma visão política de cidadania, é primordial que haja dinamismo, possibilidade de exercício de pensamento reflexivo e a capacidade de integrar arte, cultura e valores.

A relação estabelecida entre educador e educando, os mecanismos que levam a produção de conhecimento, a postura de indagação permanente, quando aplicadas na aprendizagem, contribuem para o 'aprender a aprender'. Tais medidas promovem importantes mudanças no ensino que devem ser motivo de constante reflexão no âmbito escolar.

\section{CONSIDERAÇÕES FINAIS}

A partir do panorama apresentado pelos resultados deste estudo, consideramos as várias formas de utilização das HQs válidas e pertinentes como ferramentas pedagógicas. Elas funcionam como recurso para o despertar e a consolidação do interesse e do hábito da leitura, assim como integram conhecimentos, percepções e emoções; instigam a curiosidade e a criatividade; promovem a deflagração de um processo cognitivo questionador, mais consciente e crítico, e favorecem a reflexão e a aquisição de novos conhecimentos - sua construção e reconstrução. 
Observamos que o trabalho com quadrinhos é bem aceito pelos alunos, mesmo quando a proposta consistiu em uma produção para fins avaliativos. Sua estrutura mais leve, quanto à forma do texto, e mais 'cotidiana', próxima da linguagem falada, permite uma maior identificação com as crianças e jovens, permitindo-os se expressar através de um viés artístico e desenvolver várias áreas cognitivas. Ao falar diretamente ao imaginário da criança, as HQs preenchem suas expectativas e tornam o aprendizado mais proveitoso e divertido.

Este cenário reforça os aspectos positivos das HQs no processo educativo. Assim, acreditamos ser oportuna a divulgação desta prática junto aos educadores de modo a desmistificar tabus; romper pré-conceitos e preconceitos; dinamizar a sala de aula e proporcionar momentos mais lúdicos, divertidos e integradores, em uma perspectiva interdisciplinar e contextualizada e buscando um ensino mais significativo para os educandos. 


\section{REFERÊNCIAS}

AUGUSTO, T. G. S.; CALDEIRA, A. M. A. Dificuldades para a implantação de práticas interdisciplinares em escolas estaduais, apontadas por professores da área de ciências da natureza. Investigação em Ensino de Ciências, v. 12, n. 1, 2007.

BAHLS, T. M.; REZENDE, C. C. As tiras em quadrinhos em ensino/aprendizegem de espanhol como língua estrangeira. In: CONGRESSO NACIONAL DE EDUCAÇÃO - EDUCERE, 10.; 2011, Curitiba, PR. Anais... Curitiba, PR: PUC do Paraná.

BERGER, P.; LUCKMANN, T. A construção social da realidade. 6 ed. Petrópolis, RJ: Editora Vozes, 1985.

BOFF, E. Ambiente para a construção cooperativa de Histórias em Quadrinhos. 2000. 138f. Dissertação (Mestrado em Ciência da Computação) - Programa de Pós-Graduação em Ciência da Computação, PUC do Rio Grande do Sul, Rio Grande do Sul.

BRASIL. Secretaria de Educação Fundamental. Parâmetros curriculares nacionais.- Brasília: MEC/SEF, 1997.

CARUSO, F.; SILVEIRA, C. Quadrinhos para a cidadania. História, Ciências, Saúde - Manguinhos, v. 16, n.1, 2009.

CARVALHO, J. A. B.; BARBEIRO, L. F. Reproduzir ou construir conhecimento? Funções da escrita no contexto escolar português. Revista Brasileira de Educação, v. 18, n. 54, 2013.

CARVAlHO, A. C. de; OLIVEIRA, M. P. de. Os Quadrinhos e uma Proposta de Ensino de Leitura. In: ENCONTRO DOS NÚCLEOS DE PESQUISA DA INTERCOM, 6.; 2004, Porto Alegre, RS. Anais... Porto Alegre, RS, PUC do Rio Grande do Sul.

CIRNE, M. Quadrinhos, sedução e paixão. Petrópolis, RJ: Editora Vozes, 2000.

FANARO, M. A.; OTERO, M. R.; GRECA, I. M. Las Imágenes en los Materiales Educativos: las ideas de los profesores. Revista Electrónica de Enseñanza de las Ciencias, v. 4, n. 2, 2005.

FAZENDA, I. C. A. Interação e interdisciplinaridade no ensino brasileiro: Efetividade ou ideologia. 5 ed. São Paulo: Edições Loyola, 2002.

FONTOURA, H. A. da; PIERRO, G. M. de S.; CHAVES, I. M. A. B. Didática: do ofício e da arte de ensinar. Niterói: Intertexto, 2011.

FREINET, C. Para uma Escola do Povo. São Paulo: Martins Fontes, 1966.

. Conselho aos pais. 2 ed. Lisboa: Estampa, 1974.

FREIRE, P. Pedagogia da Autonomia: saberes necessários à prática educativa. 2 ed. Rio de Janeiro: Paz e Terra, 1997.

Educação e participação comunitária. In: Política e educação - Coleção Questões da nossa época. 5 ed. São Paulo: Cortez, 2001.

GOMES, A. M. de A.; ALBUQUeRQUE, C. M. de; CATRIB, A. M. F.; SILVA, R. M. da; NATIONS, M. K.; ALBUQUERQUE, M. F. Os saberes e o fazer pedagógico: uma integração entre teoria e prática. Educar, n. 28. 
KAMEL, C. R. L. Ciências e quadrinhos: explorando as potencialidades das histórias como materiais instrucionais. 2006. 113f. Dissertação (Mestrado em Ensino em Biociências e Saúde) - Programa de PósGraduação em Ensino em Biociências e Saúde, Instituto Oswaldo Cruz, Rio de Janeiro.

LINSINGEN, L.V. Mangás e sua utilização pedagógica no Ensino de Ciências sob a perspectiva CTS. Ciência \& Ensino, v. 1, 2007. Edição especial.

MACHADO, F. P. Palestra ministrada durante o III SENAFE - Seminário Nacional de Filosofia e Educação: Confluências, 2009, Santa Maria, RS. Anais... Santa Maria, RS: UFSM, 2009.

MEHES, R.; MAISTRO, V. I. de A. A aprendizagem de Biologia mediada por quadrinhos e/ou charges. Revista Eletrônica Pró-Docência - UEL, n. 1, v. 1, 2012. Disponível em: http://www.uel.br/revistas/prodocenciafope. Acessado em 17 de novembro de 2013.

MOREIRA, M. A. Aprendizagem Significativa. Brasília: Editora UnB, 1999.

. Teorias de aprendizagem. São Paulo: EPU, 2011.

MOYA, A de. Shazam! 3ª ed. São Paulo: Perspectiva (Debates, 26), 1977.

PALHARES, Marjory Cristiane. História em quadrinhos: uma ferramenta pedagógica para o ensino de História. Portal Educacional do Estado do Paraná - Dia a Dia Educação, PR, 2008. Disponível em: <www. diaadiaeducacao.pr.gov.br/ portals/pde/arquivos/2262-8.pdf>. Acesso em: abr. 2010.

PEREIRA, E. G. C. Educação Ambiental na escola: Ações Pedagógicas no contexto Lixo-Água-Saúde. 2008. 145f. Dissertação (Mestrado em Ensino em Biociências e Saúde) - Programa de Pós-Graduação em Ensino em Biociências e Saúde, Instituto Oswaldo Cruz, Rio de Janeiro.

PEREIRA, E. G. C; FONTOURA, H. A. da. Oficinas de Histórias em Quadrinhos como recurso de avaliação. Latin American Journal in Science Education. A publication sponsored by the Latin American Science Education Research Association. No prelo a.

. Educação Ambiental (EA) na perspectiva do ensino de Ciências. Revista Interacções, No prelo b.

PEREIRA, E. G. C.; SANTOS, T. C. dos. O uso de oficinas de histórias em quadrinhos como instrumento de avaliação no ensino de Ciências. In: SIMPÓSIO EM ENSINO DE CIÊNCIAS E MEIO AMBIENTE DO RIO DE JANEIRO, 1; 2009, Volta Redonda, RJ. Anais... Volta Redonda, RJ: UNIFOA, 2009.

. A utilização de oficinas de historias em quadrinhos em um processo avaliativo. Revista Práxis, ano 5, ago. 2013a. Edição especial.

A visão de licenciandos em Química quanto ao uso de textos e histórias em quadrinhos como instrumentos pedagógicos. In: MEMBIELA, P.; CASADO, N.; CEBREIROS, M. I. (Eds.), Retos y perspectivas en la enseñanza de las ciencias. Educación Editora: Ourense, 2013b. cap. 53, p. 323-328.

PIAGET, J. A equilibração das estruturas cognitivas. Rio de Janeiro: Zahar, 1976.

PIZARRO, M. V. Histórias em Quadrinhos e o Ensino de Ciências nas séries iniciais: Estabelecendo relações para o Ensino de conteúdos curriculares procedimentais. 2009. 188f. Dissertação (Mestrado em Educação para a Ciência) - Universidade Estadual Paulista Júlio de Mesquita Filho, Bauru, SP, 2009.

SANTOS, A. de S. dos. O eclipse solar em história em Quadrinhos: um recurso para o ensino de astronimia. 2008. 88f. Monografia (Licenciatura em Ciências Biológicas) - Universidade do Estado do Rio de Janeiro, Rio de Janeiro, RJ, 2008. 
SANTOS, F. F. P. dos. O lobo da estrada e as histórias em quadrinhos como recurso didático. Athena: Revista Científica de Educação, v. 8, n. 8, 2007.

SANTOS, R. E. dos. A história em quadrinhos na sala de aula. In: CONGRESSO ANUAL EM CIÊNCIA DA COMUNICAÇÃO, 26.; 2003, Belo Horizonte, MG. Anais... Belo Horizonte, MG: INTERCOM, 2003.

SANTOS, R. E.; VERGUEIRO, W. Histórias em quadrinhos no processo de aprendizado: da teoria à prática. EccoS - Revista Científica, n. 27, 2012.

SANTOS, T. da C. dos; PEREIRA, E. G. C. Avaliação de oficinas de histórias em quadrinhos como metodologia introdutória no Ensino de Ciências. In: SIMPÓSIO EM ENSINO DE CIÊNCIAS E MEIO AMBIENTE DO RIO DE JANEIRO, 1.; 2009, Volta Redonda, RJ. Anais... Volta Redonda, RJ: UNIFOA, 2009.

. Oficinas de Histórias em Quadrinhos como instrumento de avaliação no ensino de Ciências. In: ENCONTRO NACIONAL DE PESQUISA EM EDUCAÇÃO EM CIÊNCIAS - ENPEC, 7.; 2011, Campinas, SP. Anais... Campinas, SP: UNICAMP, 2011.

Histórias em quadrinhos como recurso pedagógico. Revista Práxis, n. 9, 2013a.

Oficinas de Histórias em Quadrinhos como recurso pedagógico no ensino de Ciências. Revista Enseñanza de las Ciencias, Barcelona, n. extra, 2013b.

SAUL, A. M. Avaliação Educacional. Série Ideias, São Paulo: FDE, 1994.

SILVA, K. S. As Histórias em Quadrinhos como fator didático-pedagógico: alguns aspectos da sua produção acadêmica entre 1990 e 2002. In: CONGRESSO NACIONAL DE EDUCAÇÃO - EDUCERE, 10.; 2011, Curitiba, PR. Anais... Curitiba, PR, 2011.

SILVA, R. S. da; OLIVEIRA, S. C. A. de; MODESTO, A. Histórias em Quadrinhos: a realidade no papel. Periódico de Divulgação Científica da FALS, v. 5, n. 10, 2011.

SOARES, S. E. M.; RIBEIRO, L .B. M. Avaliação formativa: um desafio para o professor. In: CONGRESSO BRASILEIRO DE ENSINO DE ENGENHARIA - COBENGE, 29.; 2001, Porto Alegre, RS. Anais... Porto Alegre, RS, 2001. Disponível em: <http://www.abenge.org.br/CobengeAnteriores/2001/trabalhos/APP016. pdf $>$. Acessado em: 01 maio 2013.

TESTONI, L. A. Um corpo que cai: As Histórias em Quadrinhos no Ensino de Física, 2004, 158 fls. Dissertação (Mestrado em Educação). Faculdade de Educação da Universidade de São Paulo, São Paulo, 2004.

VARGAS, S. L.; MAGALHÃES, L. M. O gênero tirinhas: uma proposta de sequência didática. Educação em Foco, v. 16, n. 1, 2011.

VYGOTSKY, L. S. A formação social da mente. São Paulo: Martins Fontes, 1988.

Pensamento e linguagem. 3. ed. São Paulo: Martins Fontes, 1991. 